Heat Transfer-Asian Research, 33 (1), 2004

\title{
Design of Miniature Loop Heat Pipe
}

\author{
C.I. Chu, ${ }^{1}$ S.C. Wu, ${ }^{2}$ P.L. Chen, ${ }^{1}$ and Y.M. Chen ${ }^{1}$ \\ ${ }^{1}$ Department of Mechanical Engineering, National Taiwan University, Taipei, Taiwan \\ ${ }^{2}$ Department of General Education, National Defense University, Taipei, Taiwan
}

\begin{abstract}
In the present study, the loop heat pipe (LHP) was miniaturized for application to electronic cooling. According to the capillary limitation, the wick structure parameters that would affect the heat transfer capacity were analyzed theoretically. Among the various wick parameters, this study especially investigated the effect of wick thickness, which has rarely been mentioned in the literature. Here, various thicknesses were analyzed theoretically and then tested experimentally. The results showed that the temperature on the evaporator wall dropped with decreasing wick thickness. This effect would lead to the raising of heat transfer capacity and the descending of thermal resistance. According to the analysis and the practical demand for electronic cooling, a miniature LHP was fabricated with the evaporator outer diameter of $13 \mathrm{~mm}$ and the evaporator length of $50 \mathrm{~mm}$. The testing results showed that, at the allowable working temperature of $80{ }^{\circ} \mathrm{C}$, the maximum heat transfer capacity was up to $200 \mathrm{~W}$ and the thermal resistance was $0.17^{\circ} \mathrm{C} / \mathrm{W}$. (C) 2003 Wiley Periodicals, Inc. Heat Trans Asian Res, 33(1): 42-52, 2004; Published online in Wiley InterScience (www.interscience.wiley.com). DOI 10.1002/htj.10133
\end{abstract}

Key words: loop heat pipe, wick structure, electronic cooling

\section{Introduction}

LHP technology was first developed by Maidanik and colleagues in the mid-1980s [1], and has since been employed in the cooling system for space shuttles or satellites. Figure 1 shows a schematic diagram of the LHP. A typical LHP system is composed of evaporator, condenser, compensation chamber, vapor line, and liquid line. Among the LHP components, the wick structure exists only in the evaporator, and the other components are constructed by a smooth tube. This feature allows the LHP to transfer large amounts of heat over a long distance.

As shown in Fig. 1, heat is acquired at the evaporator through the vaporization of working fluid. The vaporization occurs in the wick's surface that interfaces with the heated evaporator wall. The capillary force produced by evaporating meniscus would pump the vapor through the vapor line to the condenser. After being reliquefied, the working fluid is subcooled and returned through the liquid line to the evaporator. Before flowing into the liquid core, the working fluid was cached in the

Contract grant sponsor: National Science Council of Taiwan (NSC 90-2212-E-002-186),

(C) 2003 Wiley Periodicals, Inc. 


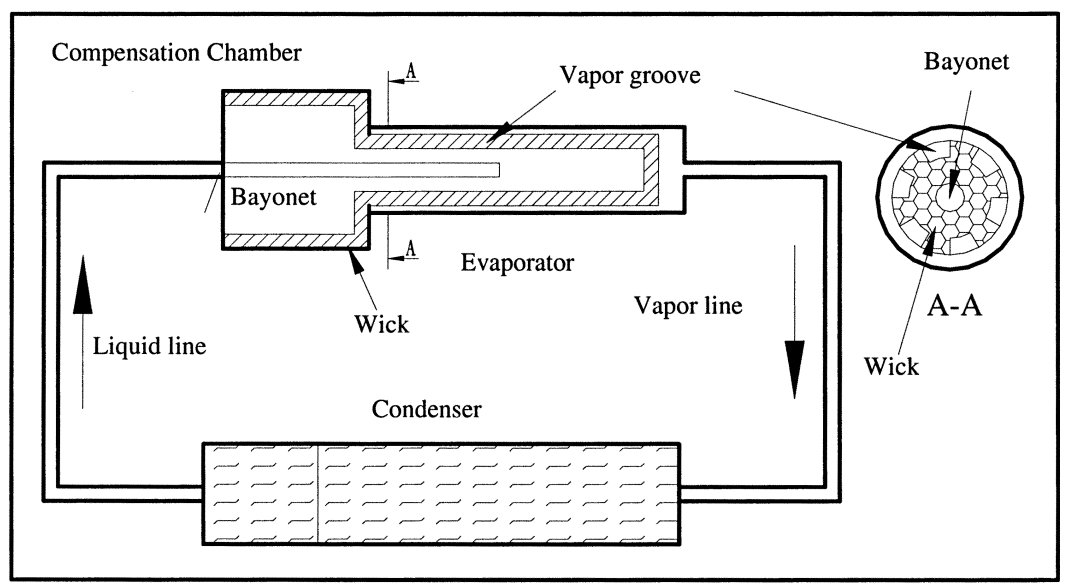

Fig. 1. Schematic of LHP.

compensation chamber which provides a swing volume to accommodate liquid volume changes in the loop due to heat load variation or sink temperature variation.

Recently, the LHP was considered a promising cooling method for the computer industry. Attention was thus paid to miniaturize the LHP for electronic cooling [2-4]. Since the power of electronic devices has grown with each passing day, the present effort seeks to develop a miniature LHP with higher heat transfer capacity. To fabricate an LHP whose geometry size was miniaturized, the wick structure parameters would be analyzed in advance according to the LHP limitations. Through the analysis, the wick parameters were designed to achieve a demand heat transfer capacity of $200 \mathrm{~W}$. To verify the theoretical analysis, a miniature LHP was then fabricated and its performance was tested. Among the various wick parameters, the wick thickness which has rarely been mentioned in the literature is of special interest in this paper.

\section{Nomenclature}

$\begin{array}{ll}D: & \text { tube diameter, } \mathrm{mm} \\ g: & \text { gravity, } \mathrm{m} / \mathrm{s}^{2} \\ H: & \text { vertical height between the axes of evaporator and condenser, } \mathrm{m} \\ h_{f g}: & \text { latent heat of vaporization, } \mathrm{W} / \mathrm{g} \\ K_{\mathrm{w}}: & \text { permeability, } \mathrm{m}^{2} \\ L: & \text { length, } \mathrm{mm} \\ \dot{m}: & \text { mass flow rate, } \mathrm{kg} / \mathrm{s} \\ P: & \text { pressure, } \mathrm{Pa} \\ Q: & \text { heat transfer rate, } \mathrm{W} \\ R: & \text { thermal resistance, }{ }^{\circ} \mathrm{C} / \mathrm{W} \\ r_{c}: & \text { pore radius, } \mu \mathrm{m} \\ r_{h}: & \text { hydraulic radius of vapor groove, } \mathrm{mm} \\ T_{c, \text { ave }}: & \text { average temperature of condenser, }{ }^{\circ} \mathrm{C} \\ T_{c, i n}: & \text { temperature of the condenser inlet, }{ }^{\circ} \mathrm{C} \\ T_{c, \text { out }}: & \text { temperature of the condenser outlet, }{ }^{\circ} \mathrm{C}\end{array}$




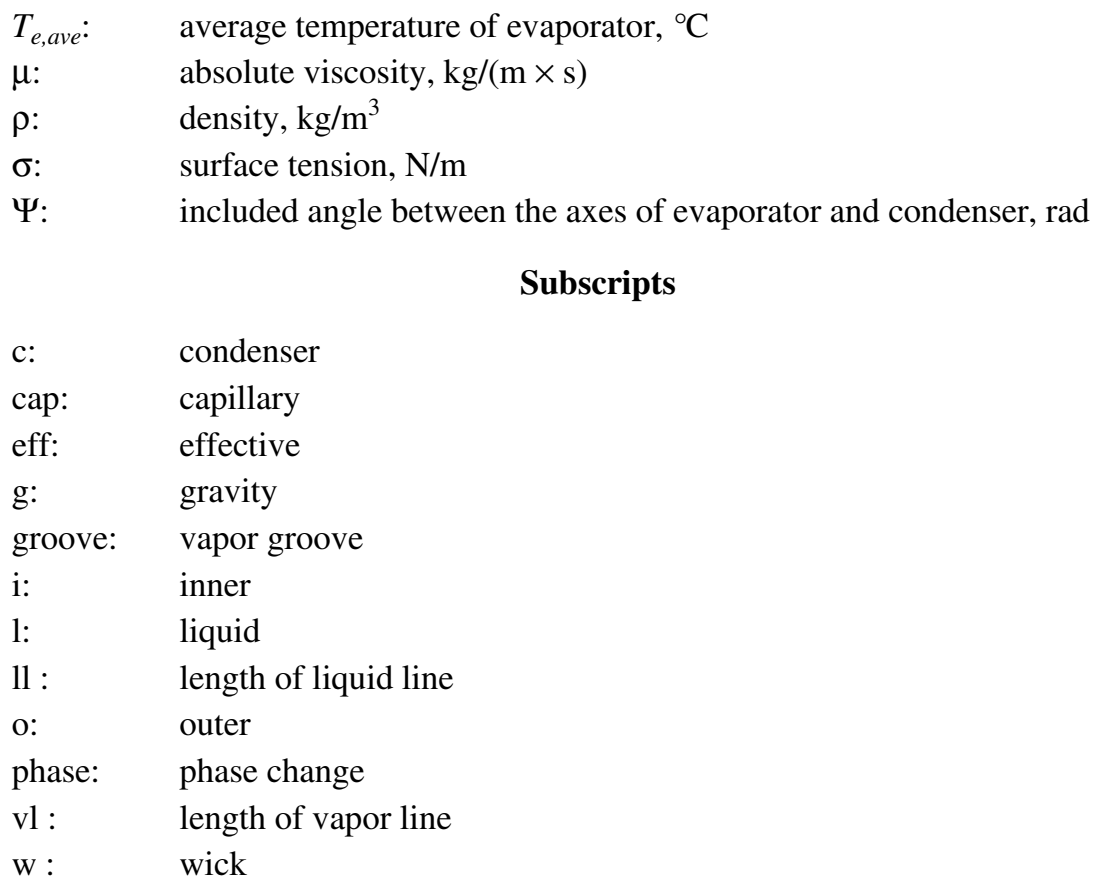

\section{Theoretical Analysis}

It is the evaporating meniscus in the wick pumping the working fluid in an LHP. So as to generate enough capillary head to balance the pressure drops in all sections of the working fluid circulation, the meniscus would adjust its curvature in accordance with the heating intensity. When the heating power increases, both the vapor and liquid flow rates are raised. The flow frictions in the tubes hence increase. For balance, the curvature of meniscus would become larger. Once the heating power increased continuously but the curvature could not become any larger, the dry-out phenomenon would occur since the capillary head could not balance all the pressure drops. At this time, the capillary force reaches a maximum. Condition of balance of the capillary head and the sum of pressure drops in all sections of the working fluid circulation could be expressed as follows:

$$
\Delta P_{\text {cap }}=\frac{2 \sigma}{r_{c}} \geq \Delta P_{v l}+\Delta P_{l l}+\Delta P_{w}+\Delta P_{\text {phase }}+\Delta P_{\text {groove }}+\Delta P_{g}+\Delta P_{c}
$$

By analyzing the various pressure drops, the maximum heat transfer capacity could also be derived as

$$
Q \leq \frac{\frac{2 \sigma}{r_{c}}-\rho g H \sin \Psi}{\frac{\mu_{l}}{2 \pi h_{f g} \rho_{l} K_{W} L_{W}} \ln \left(\frac{D_{o}}{D_{i}}\right)+\frac{8 \mu_{v} L_{\text {groove }}}{\pi \rho_{v} r_{h}^{4} h_{f g}}+\frac{128 L_{v} \mu_{v}}{\pi h_{f g} D_{i}^{4} \rho_{v}}+\frac{128\left(L_{l}+L_{\text {cond }}\right) \mu_{l}}{\pi h_{f g} D_{i}^{4} \rho_{l}}}
$$

The derivation of the equations and the details of the various pressure drops can be found in Chu's study [5]. The experimental equation of sintered powder mentioned by Chi [6] was also used here to forecast the pressure drops due to the wick. 
Here, the pressure drops caused by the wick structure were related to vapor groove size $\left(r_{h}\right)$, pore radius $\left(r_{c}\right)$, permeability $\left(K_{w}\right)$, and wick thickness $\left(t=D_{o}-D_{i}\right)$. The effects of the various wick parameters are very complicated. For example, large pore radius would lead to high permeability and hence lower the pressure drop of porous wick. However, it would simultaneously reduce the capillary force produced by evaporating meniscus. Hence, investigating the respective effects of the various wick parameters and then achieving their optimum combination would be helpful in designing a miniature LHP.

Before conducting the study on wick parameters, the material for wick structure and working fluid must be selected in advance. To serve as the thermal barrier between vapor channels and evaporator core, sintered nickel powder was considered a suitable material for wick structure, since it has low thermal conductivity. In the present study, due to the demand for high porosity, low apparent density should also be taken into account, and Inco type 255 nickel powder was hence selected. The choice of a working fluid for the LHP should be made with allowance for higher value of $d P / d T$ within the operating temperature range. Ammonia was hence chosen, even though its Merit Number and capillary height are a little lower than water.

The specifications of the other components such as condenser, liquid line and vapor line, and compensation chamber are listed in Table 1 . The demand for heat transfer capacity was set at $200 \mathrm{~W}$ for electronic cooling. Here, stainless steel was chosen as the material of tube and outer casing, because it is compatible with ammonia.

Table 1. Specifications of the Present Miniature LHP System

\begin{tabular}{|l|c|c|}
\hline \multicolumn{1}{|c|}{ PARAMETER } & VALUE & UNIT \\
\hline Compensation Chamber: & & \\
\hline -Length & 30 & $\mathrm{~mm}$ \\
\hline -Diameter & 23 & $\mathrm{~mm}$ \\
\hline Vapor Line: & & \\
\hline -Length & 460 & $\mathrm{~mm}$ \\
\hline -Diameter & 4 & $\mathrm{~mm}$ \\
\hline Liquid Line: & & \\
\hline -Length & 750 & $\mathrm{~mm}$ \\
\hline -Diameter & 3 & $\mathrm{~mm}$ \\
\hline Condenser: & 1000 & $\mathrm{~mm}$ \\
\hline - Length & 4 & $\mathrm{~mm}$ \\
\hline -Diameter & & \\
\hline Evaporator: & 50 & $\mathrm{~mm}$ \\
\hline -Length & 13 & $\mathrm{~mm}$ \\
\hline -Outer Diameter & 10 & $\mathrm{~mm}$ \\
\hline - Inner Diameter & 10 & $\mathrm{~N} / \mathrm{A}$ \\
\hline Number of Vapor Grooves & 1 & $\mathrm{~mm}$ \\
\hline Vapor Groove $r_{h}$ & 8 & $\mu \mathrm{m}$ \\
\hline Pore Radius & $1.05 \mathrm{E}-12$ & $\mathrm{~m}$ \\
\hline Permeability & $60-70$ & $\%$ \\
\hline Porosity & $1.0,1.5,2.0,2.5$ & $\mathrm{~mm}$ \\
\hline Wick Thickness & & \\
\hline
\end{tabular}


The effects of wick structure were analyzed, and their specifications were then chosen according to the demanded heat transfer capacity. The details are described below.

\subsection{Geometry of the evaporator}

According to Eq. (2) and with the wick parameters specified, the heat transfer capacity increased proportionally to the inner diameter of the evaporator. In addition, to maintain the demanded vapor groove size, the number of vapor grooves was limited. Here, $n$ is the maximum number of vapor grooves responding to the respective diameters. That is, with the diameter specified, the LHP would achieve its corresponding maximum heat transfer capacity under the condition that the number of vapor grooves was not larger than the corresponding $n$. Due to the demand for miniaturization, a compromise between the heat transfer capacity and the evaporator volume is unavoidable. To satisfy the current demand for electronic cooling, the demanded heat transfer capacity was set at $200 \mathrm{~W}$. In the present study, since the LHP was operated horizontally only, the inner diameter of evaporator was selected as $10 \mathrm{~mm}$, and the number of grooves was 10 .

\subsection{Wick structure}

The wick parameters included vapor grooves, pore radius, permeability, and wick thickness. To investigate their respective effects on heat transfer capacity, it is helpful to set the various wick parameters to their respective reference values. Here, considering the strength of structure and the convenience for fabricating, wick thickness $(t)$ and vapor groove size $\left(r_{h}\right)$ were both specified as 1 $\mathrm{mm}$. The reference pore radius $\left(r_{c}\right)$ and permeability $\left(K_{w}\right)$ were roughly estimated to be $10 \mu \mathrm{m}$ and 1 $\times 10^{-13} \mathrm{~m}^{2}$, respectively. When one of the wick parameters was investigated, the other three were specified as the reference values.

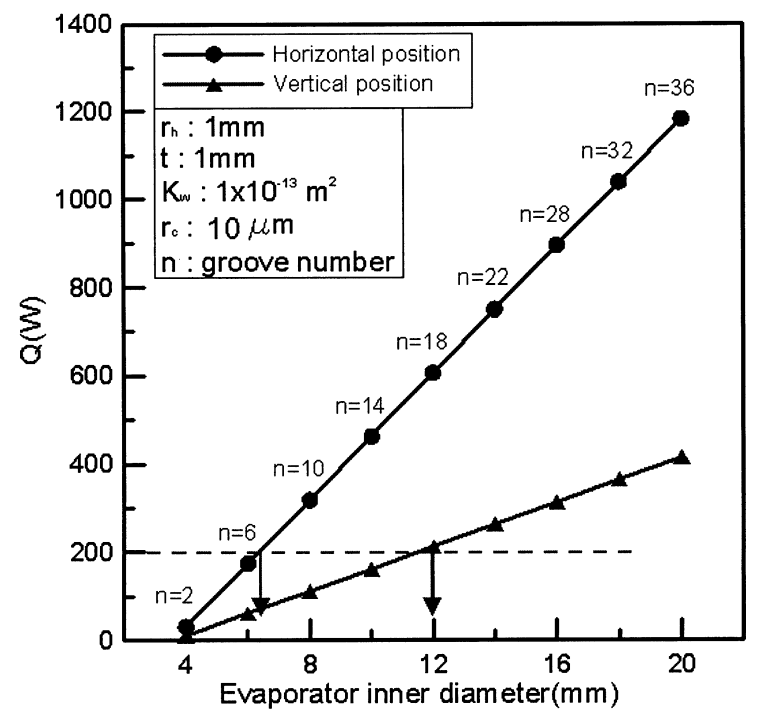

Fig. 2. Correlation between heat transfer capacity and evaporator inner radius. 
Figure 3 shows the effects of wick parameters on heat transfer capacity. As indicated by the line with $\bullet$ symbols, the heat transfer capacity of the LHP increases with increasing groove size, but does not increase any more once the hydraulic radius of the vapor groove is larger than $1 \mathrm{~mm}$. This may be because such a hydraulic radius is large enough to allow the vapor to pass through the groove easily, and a further increase would not be very meaningful.

The line indicated by $\times$ symbols reveals that the heat transfer capacity increases with decreasing pore radius. As is known, the smaller the pore radius, the higher the capillary pressure head. To satisfy the cooling demand of $200 \mathrm{~W}$, the pore radius should be no more than $10 \mu \mathrm{m}$.

However, the effect of permeability had an opposing trend. The permeability determines whether the fluid in the wick structure flows easily. The higher the permeability, the lower the flow frictions and hence the pressure drop. As indicated by the unlabeled line, when the cooling demand was $200 \mathrm{~W}$, the minimum permeability was $7 \times 10^{-14} \mathrm{~m}^{2}$.

Figure 3 also shows that the heat transfer capacity increases with decreasing wick thickness (ム). Thin wick thickness, meaning a short radial flow path in the wick, would make the liquid flow from liquid core to evaporating surface easily. However, to serve as a thermal barrier, the wick thickness should be large enough to separate the heat in the groove from the liquid core. Besides, the wick would be thick enough to maintain its structural strength. Hence, there should be a lower limit of the wick thickness.

Figure 3 reveals that the hydraulic radius of vapor groove should be larger than $1 \mathrm{~mm}$, the maximum pore radius $10 \mu \mathrm{m}$, and the minimum permeability $7 \times 10^{-14} \mathrm{~m}^{2}$. In addition, the thinner the wick is, the higher the heat transfer capacity. Since the effect of the wick thickness was rarely mentioned in prior studies, attention was hence paid to it in order to verify the theoretical analysis. In

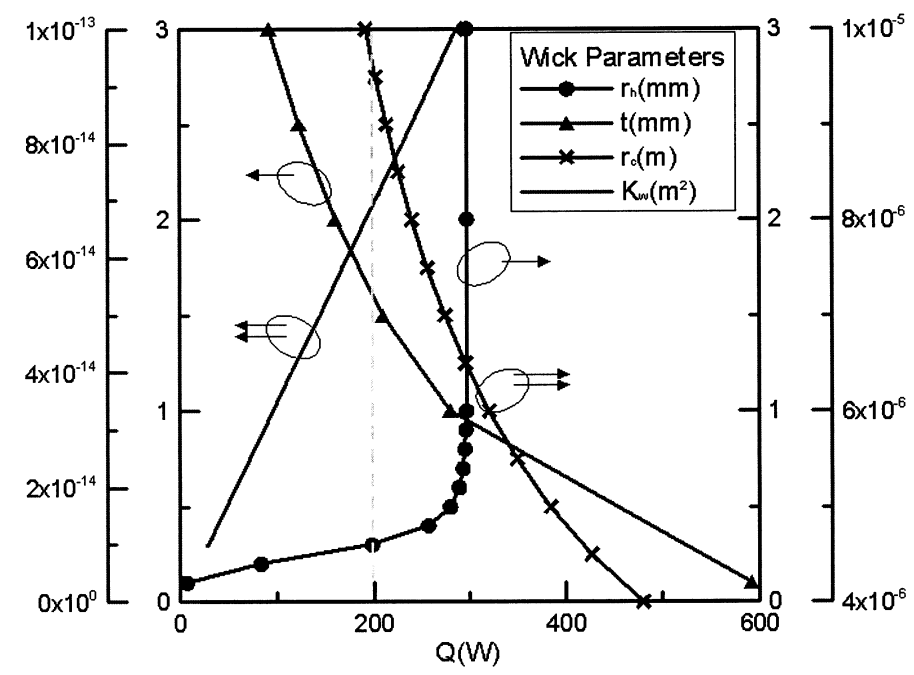

Fig. 3. Correlation between heat transfer capacity and wick structure parameters. 
the present study, experiments were conducted to investigate the effect of wick thickness, and various thicknesses were tested practically.

\section{Fabricating and Performance Testing}

\subsection{Fabricating procedures}

Here, the casing of the evaporator was made of stainless steel, and its inner diameter was 10 $\mathrm{mm}$. However, increasing the thickness would simultaneously increase the thermal resistance. Hence, the outer diameter was chosen as $13 \mathrm{~mm}$ for a compromise.

Before sintering the wick, it is necessary to fabricate the mold in advance. During sintering, the mold would bear the high temperature and could conduct heat uniformly to the metal powder. Besides, the bonding reaction between mold and powder should be avoided. Hence, graphite was considered a suitable material, and the mold was fabricated by using the electrical discharging process.

To fabricate a sintered wick structure with small pore radius and high permeability, the nickel power should be of small size and low apparent density. Inco type 255 was hence used here. Before the powder was filled, a central stick was inserted into the mold to shape the wick cannular. Hence, the wick thickness could be adjusted by varying the stick radius, and the selected thicknesses were $1.0,1.5,2.0$, and $2.5 \mathrm{~mm}$.

For the demand of high permeability, the wick was fabricated by the loose powder sintering process. According to Tracey's study [7], the sintering temperature should lie between 600 and 1000 ${ }^{\circ} \mathrm{C}$. After being tested, the sintering temperature was set at $630{ }^{\circ} \mathrm{C}$, and the sintering time was 15 minutes. During the sintering, the furnace was filled with hydrogen to serve as reduction atmosphere. The pore radius and permeability were measured as about $8 \mu \mathrm{m}$ and $1.05 \times 10^{-12} \mathrm{~m}^{2}$, respectively [5]. Figure 4 shows the finished wick structure and its feature is listed in Table 1.

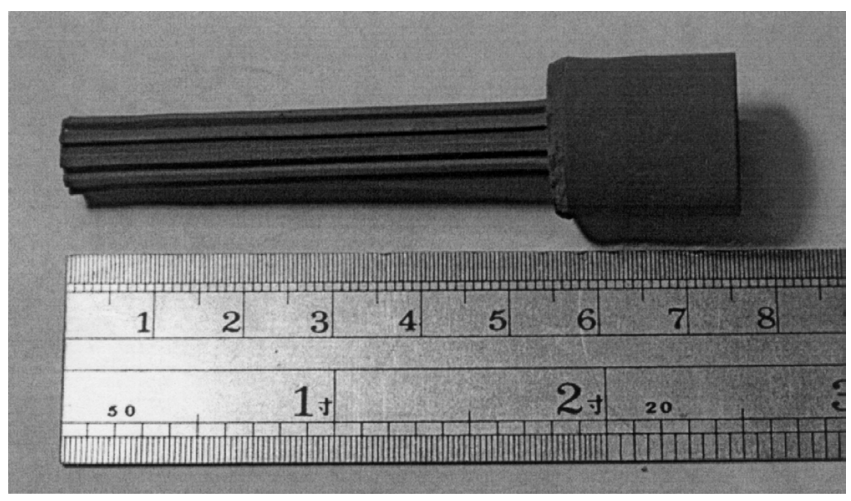

Fig. 4. The finished wick structure. 


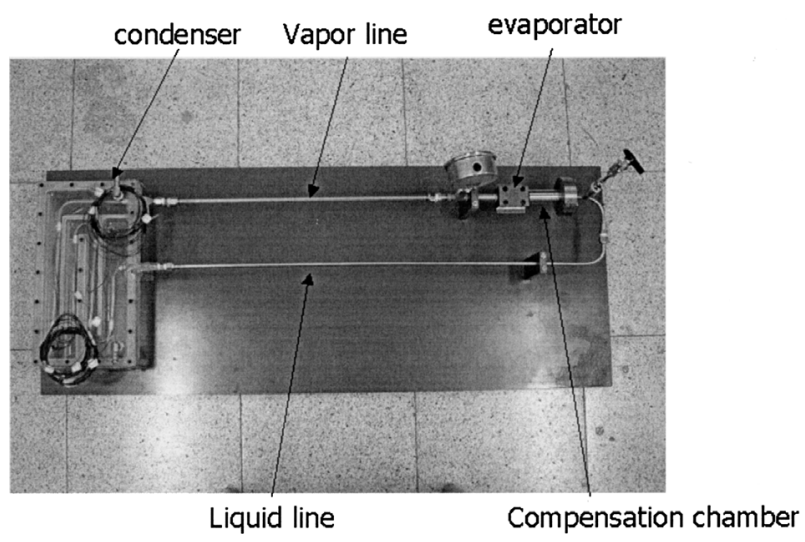

Fig. 5. The fabricated LHP system.

After all components were finished, the fabricated LHP system was attached to the vacuum and filling system. When the desired vacuum condition of $1 \times 10^{-3}$ Torr was achieved, a suitable amount of ammonia was injected into the system. Finally, the valved end was sealed up and a miniature LHP was achieved. The fabricated LHP system is shown in Fig. 5.

\subsection{Performance testing}

The test system shown in Fig. 6 was used to measure the heat transfer capacity of the LHP. Here, power supply provided the demand heating power, and the sink was simulated by a water cooler whose flow rate was controlled by a flow meter. Thermal couples measured the temperature on the evaporator and condenser, and a recorder captured the measured data. By measuring the temperature

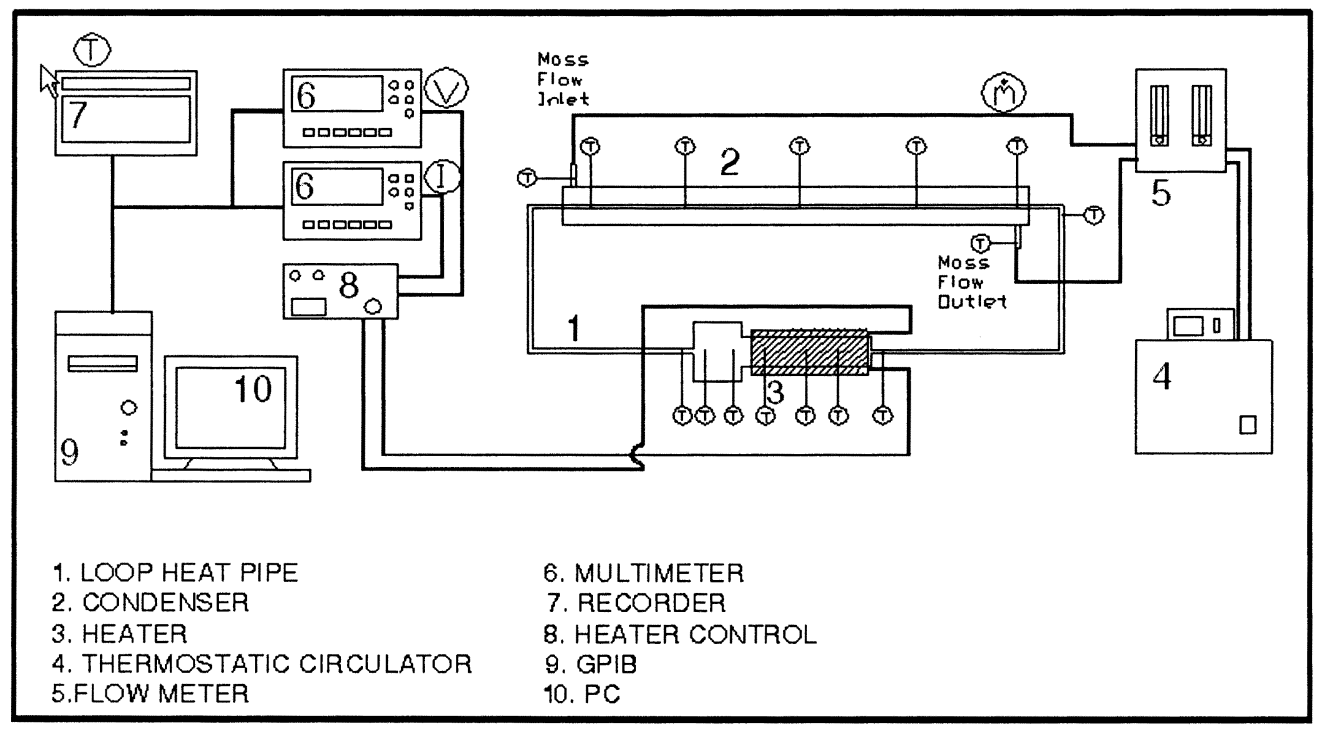

Fig. 6. Performance testing system. 
on both the inlet and outlet of the condenser, the heat transfer capacity could be obtained, and the equation was expressed as

$$
Q=\dot{m} C_{p}\left(T_{c, \text { out }}-T_{c, \text { in }}\right)
$$

The respective average temperature of the evaporator and condenser would also help to obtain the system thermal resistance, expressed as

$$
R=\left(T_{e, a v g}-T_{c, a v g}\right) / Q_{c}
$$

Here, the uncertainty of heat transfer capacity and thermal resistance were estimated to be about $4.9 \%$ and $5.5 \%$, respectively.

\section{Results and Discussion}

\subsection{Wick thickness effects}

Figure 7 reveals that with decreasing thickness, the temperature on the evaporator wall would also decrease. This is because with a thinner wick, supplying the evaporating surface with working fluid would become cooled more easily, and the temperature on the evaporator wall hence cooled down. From Eq. (4), since the thermal resistance of an LHP system was related to the temperature on the evaporator wall, such an effect would help to reduce the thermal resistance. Besides, the thinner the wick is, the lower the pressure drop caused by the wick. Summing up, as the wick thickness is decreased, not only the thermal resistance but also the pressure drop descends. Hence, decreasing the wick thickness would enhance the LHP performance substantially.

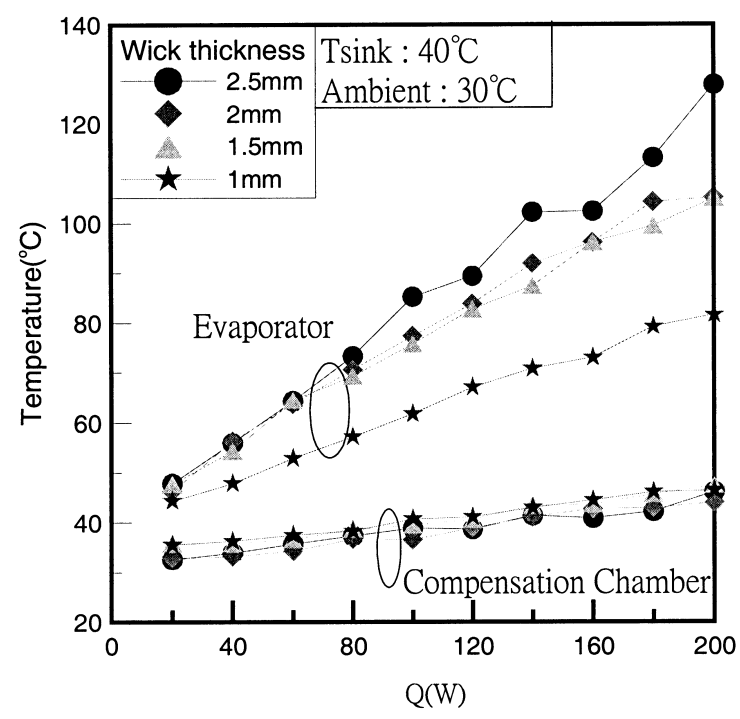

Fig. 7. The effect of wick thickness. 
On the other hand, when the thickness was decreased, both the volume of the evaporator core and compensation chamber would increase relatively. It would raise the heat leak to the evaporator core or compensation chamber, and increase the temperature of the compensation chamber. However, from the experimental results, even as the thickness decreased substantially, the temperature of the compensation chamber increased only a little. That is, the effect of decreasing wick thickness on pressure drop is much more obvious than on heat leak.

\subsection{Comparison between theory and experiment}

With the wick thickness specified at $1 \mathrm{~mm}$, the results showed that at the working temperature of $80^{\circ} \mathrm{C}$, the maximum heat transfer capacity was $200 \mathrm{~W}$ and the thermal resistance was $0.17^{\circ} \mathrm{C} / \mathrm{W}$. The experimental results shown in Fig. 8 revealed that the heat transfer capacity increased with decreasing wick thickness, and the theoretical results had a similar trend. However, the difference between theory and experiment increases with decreasing thickness.

In the compensation chamber, the degree of subcooling of working liquid was used to compensate for the heat leak. However, due to the influence of environment factor, the degree of subcooling would not always be enough. When the thickness was decreased, the heat leak would become more serious, and the degree of subcooling would not compensate for the heat leak completely. It would raise the temperature of both the compensation chamber and evaporator core, and affect the LHP performance. This is perhaps why the difference between theory and experiment increased with decreasing thickness.

The other reason is the vapor penetrating back to the evaporator core. When the heat flux increased, the generated vapor would not only flow toward the vapor channel but also penetrate to the evaporator core. It would raise the temperature of the evaporator core and lower the system performance. Once the wick thickness was decreased, the penetrating phenomenon may become more serious.

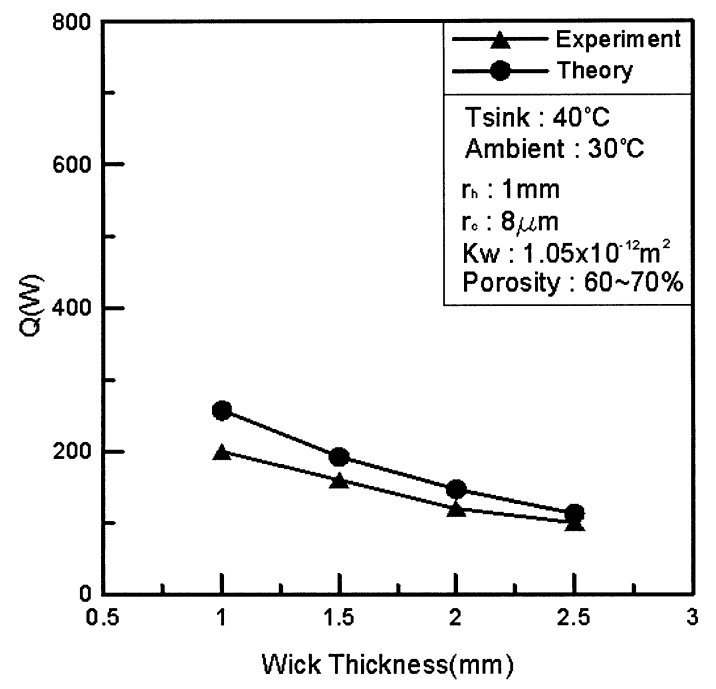

Fig. 8. Comparison between theoretical and experimental wick thickness. 


\section{Conclusion}

According to the LHP limitations, wick structure parameters including vapor groove size, pore radius, permeability, and wick thickness were analyzed theoretically. An experiment was conducted to fabricate a miniature LHP and to verify the theoretical analysis. The major results are listed below:

1. Through the theoretical analysis, the optimal parameter combination of wick structure was found, and the basis for designing an LHP was established.

2. The finished miniature LHP achieved a heat transfer capacity of $200 \mathrm{~W}$ at the working temperature of $80^{\circ} \mathrm{C}$ and the thermal resistance was $0.17^{\circ} \mathrm{C} / \mathrm{W}$.

3. The theoretical and experimental results both showed that decreasing the wick thickness would lower the evaporator temperature and enhance the LHP performance.

\section{Acknowledgments}

Financial support from the National Science Council of Taiwan (NSC 90-2212-E-002-186) is appreciated.

\section{Literature Cited}

1. Maidanik YF, Vershinin S, Kholodov V, Dolgirev J. Heat transfer apparatus. US Patent No. 4515209, May 7, 1985.

2. Baldassarre JG, Gernert NJ, Gottschlich J. Loop heat pipe for avionics thermal control. SAE Paper No. 961318, 1996.

3. Maidanik YF, Vershinin SV, Chernysheva MA. Development and tests of miniature loop heat pipe with a flat evaporator. SAE Paper No. 2000-01-2491, 2000;652-656.

4. Chen PC, Lin WK. The application of capillary pumped loop for cooling of electronic components. Appl Therm Eng 2001;21:1739-1754.

5. Chu CY. Design, fabrication and performance testing of miniature loop heat pipe. Master's thesis, National Taiwan University, 2001.

6. Chi SW. Heat pipe theory and practice. McGraw-Hill; 1976.

7. Tracey VA. Pressing and sintering of nickel powders. Int J Powder Metall Powder Tech 1984;20:281-285.

Originally published in Proceedings 2002 Symposium on Transport Phenomena and Applications, $\mathrm{p}$ 55-58, Taipei, Taiwan, ROC.

Translated by Yau-Ming Chen, Department of Mechanical Engineering, National Taiwan University, Taipei, Taiwan 106, ROC. 